\title{
PERANCANGAN SISTEM PENGUKURAN KINERJA PADA KOPERASI KOPERASI KARYAWAAN REDRYING DENGAN MENGGUNAKAN METODE BALANCED SCORECARD DAN ANALITICAL HIERARCHICAL PROCESS DI BOJONEGORO
}

\author{
Indrianawati Usman \\ Departemen Manajemen Fakultas Ekonomi dan Bisnis \\ Universitas Airlangga \\ e-mail: indrianawati@gmail.com \\ Mohammad Agung Laksono \\ Departemen Manajemen Fakultas Ekonomi dan Bisnis \\ Universitas Airlangga
}

\begin{abstract}
Abstrak
Balanced Scorecard menyediakan kerangka komprehensif yang dapat menterjemahkan tujuan strategi perusahaan kedalam set pengukuran kinerja perusahaan secara menyeluruh, sehingga sangat membantu pimpinan peruahaan dalam mengimplementasikan strateginya secara efektif. Koperasi Karyawaan Redrying Bojonegoro merupakan bisnis yang sedang berkembang pesat dengan banyak unit usaha. Penelitian ini bertujuan untuk merancang sistem pengukuran kinerja dengan metode balanced scorecard pada Koperasi. Hal ini dikarenakan balanced scorecard mengukur kinerja perusahaan dari aspek keuangan dan non keuangan, internal maupun eksternal.

Penelitian ini dilakukan dilakukan dengan men-translate visi, misi, tujuan koperasi kedalam sasaran strategik dan menyusun kedalam strategy map. Kemudian menentukan Key Performance Indicators dan validasi oleh pengurus secara focus discision group dengan dilanjutkan pembobotan KPI dengan metode Analytical Hierarchy Process.

Hasil dari ini tersusunlah model balanced sorecard koperasi dengan 14 KPI dari 10 leg indicators dan hasil pembobotan KPI dengan AHP diperoleh bahwa perspektif keuangan memiliki hasil pembobotan tertinggi dengan nilai 0.418 ; peringkat kedua perspektif Pelanggan dengan nilai 0.271; peringkat ketiga perspektif Pemebelajaran dan Pertumbuhan 0.191; dan prioritas terakhir adalah perspektif proses bisnis internal dengan nilai 0.120 .
\end{abstract}

Keywords : Sistem Pengukuran Kinerja, Balanced Scorecard, Analytical Hierarchy Process, Koperasi 


\section{Pendahuluan}

Penelitian Carrie dan Macintosh, 1993 mengidentifikasikan pentingnya untuk penurunan tujuan keseluruh organisasi dan berikut pengukuran kinerjanya pada bagian-bagian organisasi sebagai elemen-elemen penting keunggulan bersaing yang berkesinambungan. (Umit S Bititci, Allan S Carrie and Liam McDevitt,1997).

Peningkatan kinerja perusahaan merupakan hal yang penting dalam meningkatkan daya saing. Era pasar bebas, menuntut setiap perusahaan untuk dapat melaksanakan strateginya dalam menggunakan sumber daya yang dimilki untuk mencapai visi dan misis secara efektif.. Pengukuran kinerja merupakan cara untuk membantu perusahaan dalam mengimplementasikan strateginya.

Koperasi Karyawan Redrying Bojonegoro adalah bidang usaha koperasi yang didirikan 1976 yang berorientasi pada usaha pengeringan tembakau. Meskipun berbadan usaha koperasi namun telah banyak melakukan ekspansi usaha antara lain, Unit Threshing, Unit Jasa Sigaret Kretek Tangan, Unit Simpan Pinjam, Unit Pertokoan dan Distribution Centre, serta Unit Transportasi. Koperasi ini beranggotakan 409 orang serta menyerap 3407 tenaga kerja dan omzet usaha sebesar Rp. 103.787.000.000,- pertahun dari semua unit bisnisnya. Unit usaha yang dijalankan oleh koperasi menjadi semakin banyak namun koperasi saat ini hanya melakukan pengkuran kinerja dari perspektif keuangan saja. Diperlukan pengukuran kinerja yang lebih komprehensif untuk mendukung kelancaran implementasi strategi dan menjamin kesinambungan dan pertumbuhan koperasi.

Robert S. Kaplan dan David P. Norton (1996) dalam Harvard Business Review melakukan pendekatan yang mengukur kinerja dengan mempertimbangkan empat perspektif yaitu; perspektif keuangan (financial perspective), perspektif pelanggan (costumer perspektif), perspektif proses bisnis internal (internal business process perspective), serta perspektif pembelajaran dan pertumbuhan (learning and growth perpective). Metode pendekatan tersebut disebut Balanced Scorecard yang menyediakan kerangka komprehensif yang dapat menterjemahkan tujuan strategi perusahaan kedalam set pengukuran kinerja perusahaan secara menyeluruh. Pengukuran yang lebih holistic, luas, dan menyeluruh ini berdampak bagi perusahaan untuk lebih bijak dalam memilih startegi korporat dan memampukan perusahaan untuk memasuki arena bisnis yang lebih kompleks.

Balanced Scorecard dilengkapi dengan kejalasan indikator kinerja dan standar kinerja, sehingga penilaian terhadap suatu event menjadi jelas dan terukur. Dasar pemikiran bahwa setiap perspektif dapat diukur adalah adanya keyakinan bahwa "if we can measure it, we can manage it, if we can manage it, wecan achive it". Dengan Balanced Scorecard diharapkan dapat mengintegrasi energi, kemampuan, dan pengetahuan organisasi yang spesifik dari perusahaan agar mencapai long-term strategic goals.

\section{Rumusan masalah:}

Saat ini koperasi telah memiliki rencana strategi dan telah menyusun visi dan misi. Namun demikian dengan meningkatnya usaha dengan omzet yang besar, tentu saja diperlukan sarana untuk mendukung implementasi strategi agar visi dan misi serta tujuan dapat dicapai dengan baik. Untuk itu diperlukan pengukuran kinerja yang komprehensif yang dalam hal ini akan digunakan Balanca Scorecard serta penggunaan AHP dalam penyusunannya. Pengukuran kinerja akan disusun dengan meneliti praktek pengukuran kinerja koperasi saat ini terlebih 
dahulu, kemudian berdasarkan atas kondisi saat ini akan dirancang sistem pengukuran kinerja yang sesuai dengan koperasi dengan Balance scorecard dan AHP. Berikut adalah rumusan masalah penelitian :

1. Bagaimanakah sistem pengukuran kinerja yang digunakan Koperasi Karyawan Redrying Bojonegoro saat ini?

2. Bagaimanakah sistem pengukuran kinerja dengan menggunakan Balanced Scorecard pada Koperasi Karyawan Redrying Bojonegoro ?

Tujuan penelitian adalah untuk menggambarkan kondisi Mengetahui sistem pengukuran kinerja yang digunakan Koperasi Karyawan Redrying Bojonegoro saat ini dan menyusun rancangan sistem pengukuran kinerja dengan menggunakan metode Balanced Scorecard pada Koperasi Karyawan Redrying Bojonegoro.

\section{Landasan Teori Pengukuran Kinerja}

Atkinson, Banker, Kaplan, dan Young (1997:51) mengemukakan bahwa pengukuran kinerja mengukur berbagai aktivitas organisasi sehingga menghasilkan informasi umpan balik untuk melakukan perbaikan organisasi, meliputi: perbaikan perencanaan, proses, dan evaluasi. Artinya perencanaan proses dan evaluasi yang implementasinya kurang sesuai dengan seharusnya dan setelah dinilai kinerjanya menunjukan informasi yang tidak sesuai dengan tujuan, maka ketidaksesuaian itu dijadikan informasi untuk perbaikan proses perancanaan evaluasi selanjutnya. Najmi (2005: 109-122) juga menjelaskan bahwa dalam sistem pengukuran kinerja harus memenuhi tiga konsep dasar yaitu Direction, menjelaskan tentang visi, misi, dan sasaran strategis sehingga arah perusahan menjadi jelas. Process, menjelaskan bahwa perusahaan diatur oleh proses yang dikenal dengan praktek proses perbaikan dan Measures, menyatakan bahwa perusahaan mempunyai ukuran proses operasional organisasi yang berasal dari strategi dan gambaran arah perusahaan.

\section{Gambar-1}

\section{Generic Performance Measurement System design approach}

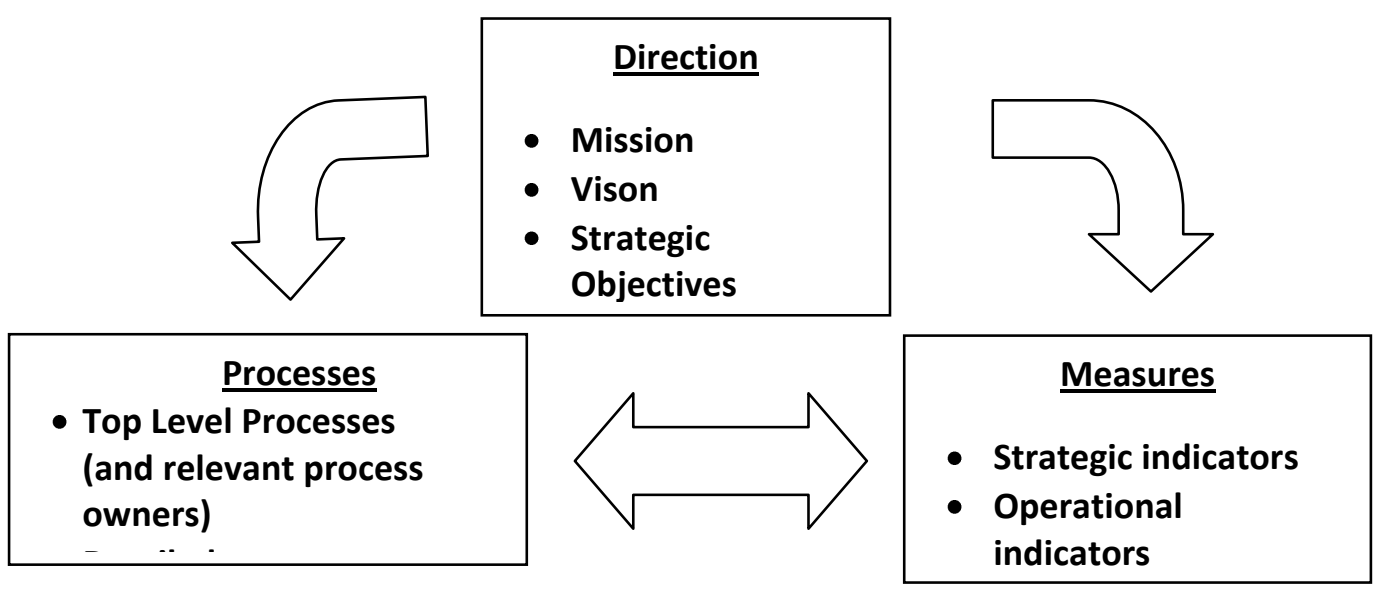

Sumber: Najmi, Manoochehr, et all. 2005. A Framework to Review Performance

Measurement System. Bussines Process Management Journal Vol.11 No.2 pp. 109122. 
Menurut Paul Niven (dalam Nidzom 2011:27), strategy map merupakan suatu gambaran grafis tentang objektif yang penting, namun dalam bentuk yang polos dan sederhana sehingga mudah dipahami oleh setiap pekerja dari tingkat atas sampai bawah. Kaplan dan Norton 2004:55 bahwa strategy map sebagai presentasi kemajuan keseluruhan organisasi dengan empat perspektif Balanced Scorecard.

\section{Balanced Scorecard}

Kaplan dan Norton (1996:8) mengatakan bahwa Balanced Scorecard merupakan sistem pengukuran kinerja masa lalu dengan pendorong utama kinerja masa depan. Tujuan dan ukuran dari Balanced Scorecard diturunkan dari visi dan misi organisasi serta strategi. Pimpinan perusahaan dapat mengkur seberapa besar berbagai unit bisnis mereka dalam menciptakan nilai bagi pelanggan dan seberapa banyak perusahaan harus meningkatkan kapabilitas internal dan investasi sumber daya manusia serta sistem yang dibutuhkan untuk meningkatkan kinerja dimasa yang akan datang. Komponen Balance Scorecard terdiri dari financial perspective, costumer perspective, process business internal perspective, serta learning and growth perspective.

\section{Perspektif Keuangan}

Ukuran kinerja keuangan memberi petunjuk apakah strategi perusahaan, implementasi, dan pelaksanaanya memberikan kontribusi atau tidak kedalam peningkatan pada perusahaan. Tujuan perusahaan biasanya berhubungan dengan profitabilitas, yang diukur dengan misalnya: Return on Asset (ROA), Return on Investment (ROI), atau Economic Value Added (EVA). Tujuan finansial lainya bisa berupa pertumbuhan penjualan yang cepat atau terciptanya arus kas.Kaplan dan Norton (1996: 48-49) menjelaskan bahwa sasaran keuangan bisa sangat berbeda tiap tahapan siklus kehidupan bisnis

Tabel-1

Measuring Strategic Financial Themes

\begin{tabular}{|c|c|c|c|c|}
\hline & \multicolumn{3}{|c|}{ Strategic Themes } \\
\hline & & $\begin{array}{c}\text { Revenue Growth and } \\
\text { Mix }\end{array}$ & $\begin{array}{l}\text { Cost Reduction / } \\
\text { Productivity } \\
\text { Improvement }\end{array}$ & Asset Utilization \\
\hline \multirow{2}{*}{ 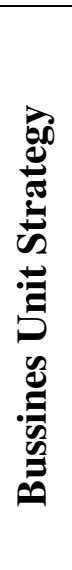 } & 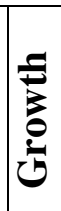 & $\begin{array}{l}\text { *Sales growth rate by } \\
\text { segment percentage } \\
\text { revenue from new product, } \\
\text { services, dan costumer }\end{array}$ & *Revenue/employee & $\begin{array}{l}\text { *Invesment } \\
\text { (percentage of sales) } \\
\text { *R\&D (percentage of } \\
\text { sales) }\end{array}$ \\
\hline & $\frac{\mathfrak{B}}{\frac{0}{\pi}}$ & $\begin{array}{l}\text { *Share of targeted } \\
\text { costumers and accounts } \\
\text { *Cross-selling } \\
\text { *Percentage revenues from } \\
\text { new applications } \\
\text { *Costumer and product } \\
\text { line profitability }\end{array}$ & $\begin{array}{l}\text { *Cost versus } \\
\text { competitors } \\
\text { *Cost reduction rates } \\
\text { *Indirect expenses } \\
\text { (percentage of sales) }\end{array}$ & $\begin{array}{l}\text { *Working capital ratio } \\
\text { (cash to cash cycle) } \\
* \text { ROCE by key asset } \\
\text { categories *Asset } \\
\text { utilization rates }\end{array}$ \\
\hline
\end{tabular}




\begin{tabular}{|l|l|l|l|}
$\overrightarrow{g^{2}}$ & $\begin{array}{l}* \text { Costumer and product } \\
\text { line profitability } \\
* \text { Percentage unprofitable } \\
\text { costumers }\end{array}$ & $\begin{array}{l}\text { *Unit cost (per unit of } \\
\text { output, per } \\
\text { transaction) }\end{array}$ & $\begin{array}{l}\text { *Playback } \\
\text { *Throughput }\end{array}$ \\
\hline
\end{tabular}

Sumber: Kaplan, Robert dan David P. Norton. 1996. Balanced Scorecard: Translating Strategy into Action. Harvard Business School Press.

\section{Perspektif Pelanggan}

Menurut Kaplan dan Norton (1996:68), dalam perspektf pelanggan perusahaan menggunakan tolak ukur untuk mengukur segmen pasar dan target pasar yang dibagi menjadi dua kelompok. Pertama, kelompok Pengukuran Konsumen Utama (Core Measurement Group). pada umumnya sama untuk semua jenis perusahaan, kelompok pengukuran ini terdiri dari pengukuran Market Share, Costumer Acqusition, Costumer Retention,.Costumer Satisfaction, dan Costumer Profitability. Kedua, kelompok Pengukuran Nilai Pelanggan (Costumer Value Proposition). Proporsi nilai pelanggan menggambarkan pemicu kinerja yang menyangkut pertanyaan apa yang harus disajikan perusahaan untuk mencapai tingkat kepuasan, loyalitas, retensi, dan akusisi konsumen yang tinggi. Atribut dari proporsi nilai konsumen meliputi, Product / Service Atribute, Costumer Relationship, serta Image and Reputation

\section{Gambar 2}

\section{The Costumer Value Propotion}

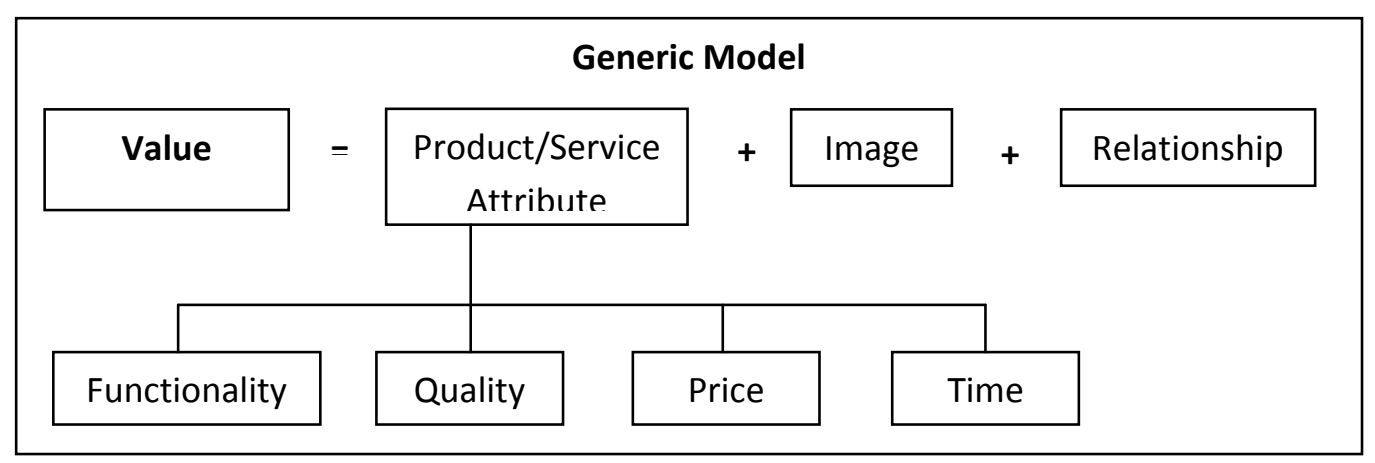

Sumber: Kaplan, Robert and David P. Norton. 1996. Using The Balanced Scorecard as a Strategic Management System. Harvard Bussiness School Press.

\section{Perspektif Proses Bisnis Internal}

Menurut Kaplan dan Norton (1996:115) setiap bisnis mempunyai tatanan proses yang unik untuk menciptakan nilai untuk konsumen dam memproduksi hasil keuanganya. Pada model proses bisnis internal dibagi menjadi tiga prinsip, yaitu Innovation yang dibagi menjadi dua, yaitu: mengidentifikasi keinginan dan kebutuhan pasar dan menciptakan produk dan jasa untuk memenuhi kebutuhan pasar tersebut. 


\section{Gambar 3}

The Internal Business Process Perspective - The Generic Value Chain Model

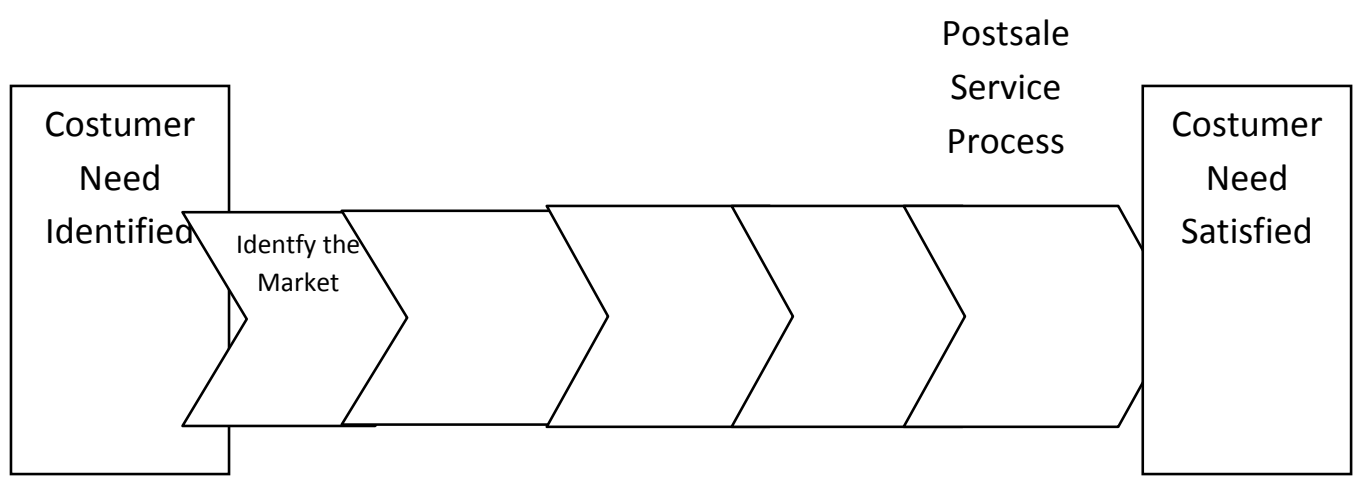

Sumber: Kaplan, Robert and David P. Norton. 1996. Balanced Scorecard: Translating Strategy into Action. Harvard Business School Press.

Semua Proses ini penting dan harus dilakuakan dengan baik oleh tiap departemen dalam organisasi. Proses innovasi dapat dipengaruhi oleh kebutuhan dari target pelanggan, fokus pada pengembangan produk baru, dan peningkatan pelayanan yang dapat memeberikan solusi lebih baik. Proses operasi terkait dengan biaya, kualitas, dan cycle time. Strategi dalam proses bisnis internal tersebut diselaraskan dengan arah tujuam dari perusahaan, sehingga dalam hali ini Balanced Scorecard hanya berfungsi sebagai penerjemah dan penghubung tolak ukur dengan strategi perusahaan

\section{Perspektif Pemebelajaran dan Petumbuhan}

Perspektif ini berkaitan dengan manusia, sistem, dan prosedur organisasi, oleh karena itu perspektif inilah penggerak dari ketiga perspektif yang lainya. Menurut Soetjipto Budi.W (1997:23) tujuanya dimasukanya kinerja ini adalah untuk mondorong perusahaan menjadi organisasi belajar sekaligus pendorong pertumbuhan. Kaplan dan Norton (1996:127) menjelaskan bahwa dalam Balanced Scorecard pada organisasi jasa dan manufaktur terdapat tiga kategori pemebelajaran dan pertumbuhan, yaitu Employee Capabilities, Information System Capabilities dan Motivation, Empowerment, and Alignment. Ketiga faktor tersebut digambarkan sebagai faktor penggerak performasi (enablers), yang hubunganya dengan pengukuran inti (core measurement) dapat digambarkan sebagai berikut: 


\section{Gambar 4}

The Learning and Growth Measurement Framework

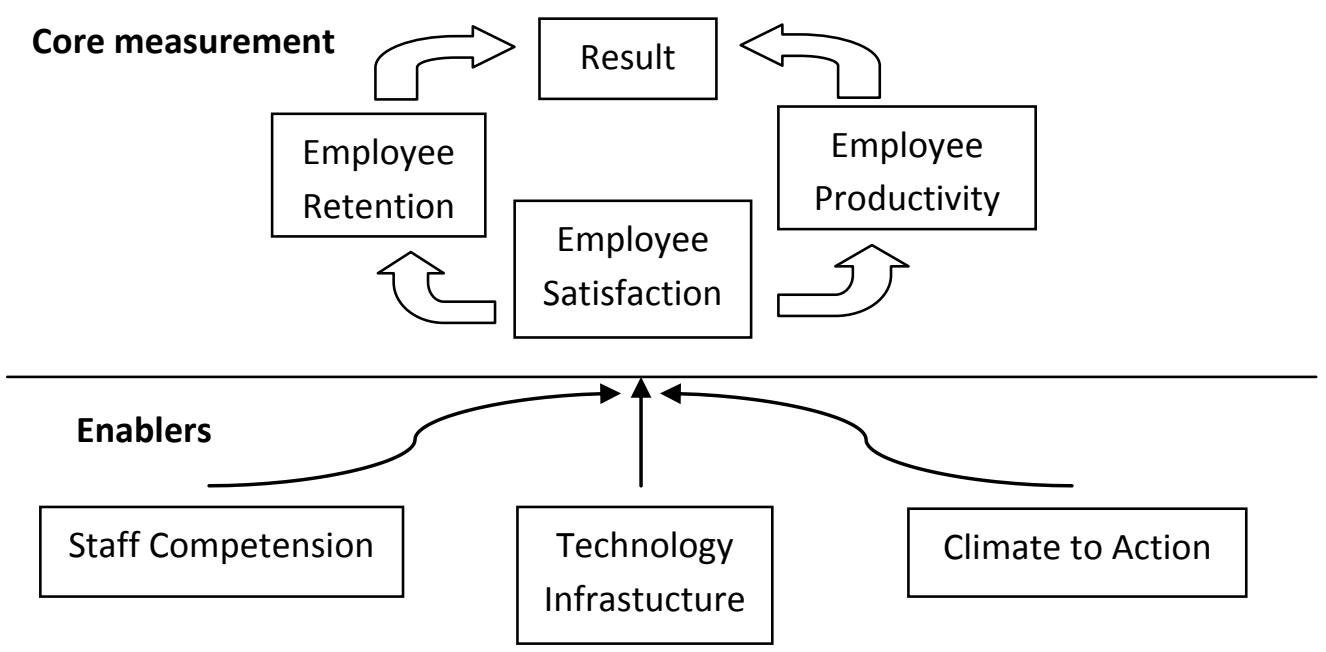

Sumber: Kaplan, Robert and David P. Norton. 1996. Balanced Scorecard: Translating Strategy into Action. Harvard Business School Press.

Balanced Scorecard dapat membantu menghubungkan visi dan strategi dengan empat perspektif secara seimbang dimana dtunjukan gambar dibawah ini:

\section{Gambar 5}

\section{Hubungan Visi dan Strategi dengan Balanced Scorecard}

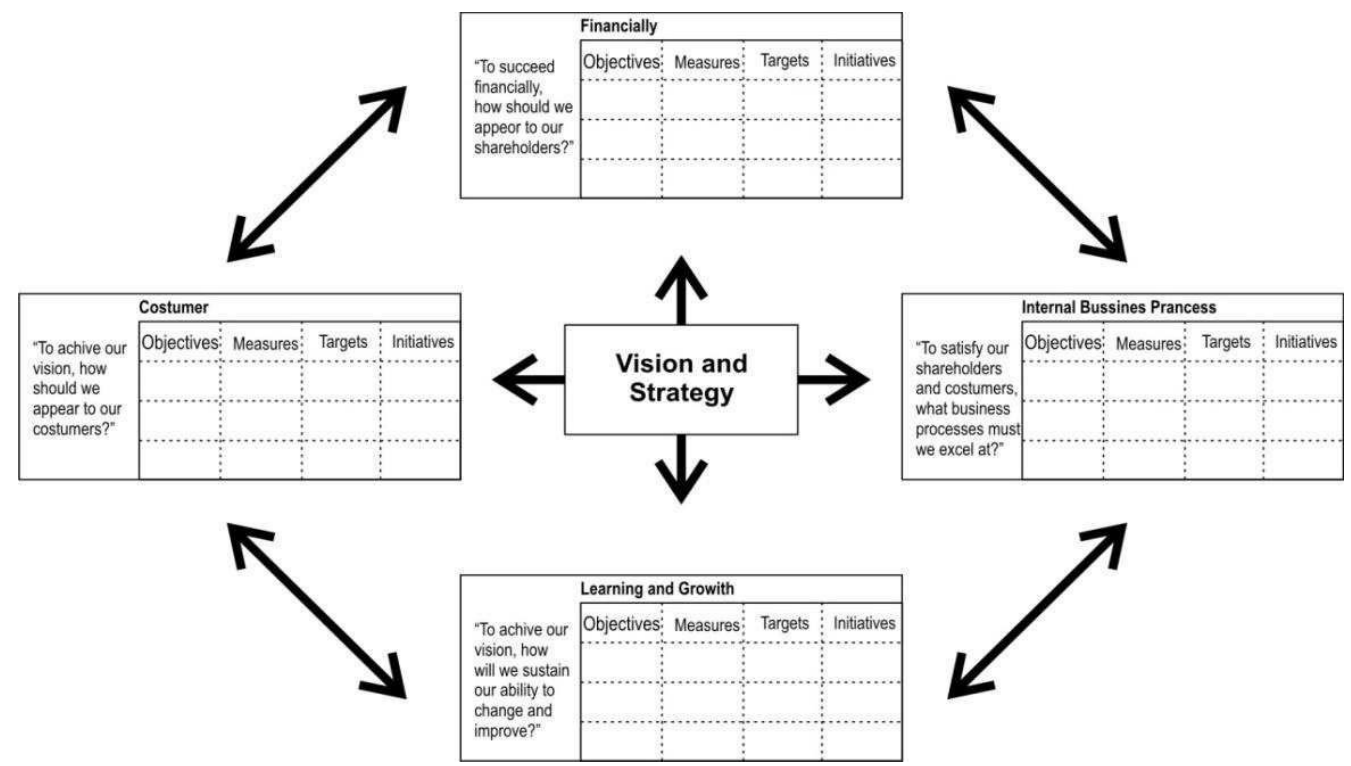

Sumber: Kaplan, Robert and David P. Norton. 2007. Using The Balanced Scorecard as a Strategic Management System. Harvard Bussiness School Press. 
Visi dan dan Strategi diterjemahkan kedalam empat perspektif yang kemudian oleh masing masing perspektif visi dan strategi tersebut dinyatakan dalam bentuk tujuan yang ingin dicapai oleh organisasi, ukuran dari tujuan, target yang diharapkan dimasa yang akan datang, serta inisiatif - inisiatif atau program yang harus dilaksanakan untuk memenuhi tujuan tujuan strategis. Kaplan dan Norton (1996) juga menjelaskan bahwa Balanced Scorecard merupakan suatu konsep manajemen yang membantu menerjemahkan strategi ke dalam tindakan. Perusahaan - perusahan inovatif dalam menngunakanya sebagai suatu sistem manajemen strategis untuk mengolola strategi perusahaan sepanjang waktu.

\section{Analytical Hierarchy Process}

Analytical Hierarchy Process (AHP) pertama kali diperkenalkan Saaty pada tahun 1971. Sejak pengenalannya AHP telah menjadi metode multiple-criteria decision making yang paling banyak digunakan dan telah memecahkan masalah terstuktur. AHP fokus pada pembuatan serangkaian perbandingan berpasangan. Perbandingan ini digunakan untuk menentukan hierarki yang harus diprioritaskan terlebih dahulu. Dengan demikian, AHP dapat membantu pengambilan keputusan. Jurnal Saaty (dalam Chandra, 2013) menyatakan bahwa untuk membuat sebuah keputusan didalam teknik AHP diperlukan langkah - langkah sebagai berukut:

a. Menentukan masalah dan memutuskan solusi apa yang akan digunakan.

b. Struktur hierarki keputusan dari atas dengan tujuan keputusan, kemudian sasaran dari perspektif melalui level menengah (berisi kriteria dan elemen - elemen yang berhubungan), sampai level terendah (yang biasanya berisi langkah alternatif)

c. Membuat matriks perbandingan berpasangan. Tiap elemen di level lebih atas digunakan untuk membandingkan elemen - elemen di level tersebut dengan elemen dibawahnya.

d. Menggunakan prioritas yang diperoleh dari membandingkan bobot prioritas di level tersebut dengan level dibawahnya. Lakukan ini untuk tiap elemen.

Untuk membuat perbandingan, dibutuhkan skala dari angka yang mengindikasikan berapa banyak elemen yang lebih penting, atau elemen apa saja yang lebih dominan. Pada umumnya nilai yang ditetapkan berada di antara 1 sampai 9.

\section{Metode Penelitian}

Pendekatan penelitian yang digunakan untuk menjawab rumusan masalah dalam penelitian yaitu metode kualitatf yang menitikberatkan analisis terhadap penyebab suatu masalah dan mencari solusi untuk memcahkan masalah tersebut berdasarkan data yang didapat di lapangan. Penelitian kualitatif menurut Maxfied dan Nazir (1998) merupakan suatu pendekatan yang menggunakan data berupa kalimat tertulis, lisan, perilaku, fenomena, peristiwa, pengetahuan atau objek studi.

Teknik yang digunakan peneliti untuk mengumpulkan data primer antara lain dengan wawancara, diskusi, dan penyebaran kuisioner kepada pimpinan pengurus, pengawas, dan direksi koperasi. Melakukan wawancara dan mengadakan FGD.

Adapun tahap-tahap penelitian adalah sebagai berikut:

1. Men-translate Visi, Misi, Tujuan Perusahaan serta Isu Startegik ke dalam Sasaran Strategis melalui pengajuan pertanyaan guna menetapkan sasaran strategis yang 
menjadi kunci sukses keberhasilan melalui pembangunan isu strategis perusahaan dalam setiap perspektif Balanced Scorecard.

2. Menyusun Strategy Map

a) Mengidentifikasikan sasaran strategis dan menjelaskan hubungan sebab akibatnya melalui wawancara dengan pimpinan Koperasi.

b) Memvisualisaikan strategy map. Sasaran strategis digambarkan akan hubungan panah - panah yang mengindikasikan adanya hubungan sabab akibat.

3. Penentuan Lead Indicator, Lag Indicator, dan Inisiatif Startegis

Penyusunan sasaran strategis pada tiap perspektif Balanced Scorecard serta menentukan inisiatif stategis atau kegiatan yang dilakukan untuk mencapai sasaran strategis, lead indicator (pemicu untuk mencapai sasaran yang ditetapkan sebagai target), dan lag indicator (keberhasilan yang dicapai sasaran strategis). Penetapan ini disebut dengan KPI (Key Performance Indicator)

4. Validasi Key Performance Index (KPI)

Validasi KPI ini dilakukan oleh pimpinan Koperasi, bertujuan untuk mengetahui ukuran apa saja yang dibutuhkan dan disetujui untuk melakukan pengukuran kinerja dengan metode Balanced Scorecard.

5. Pembobotan KPI dengan Metode AHP

Pengumpulan data dilakukan dengan cara mmberikan kuisioner dalam bentuk pembobotan KPI. Proses pembobotan KPI dilakukan oleh pimpinan Koperasi Kareb dengan metode Focus Group Discusion. Hal ini dengan tujuan memberi peringkat KPI yang memiliki kontribusi terbesar hingga terkecil pada organisasi. Data pembobotan AHP ini diperhitungkan dengan software expert choice. Pembobotan AHP ini harus memiliki syarat konsistensi $10 \%$ agar valid dan konsisten.

\section{Hasil dan Pembahasan Identifikasi Visi dan Misi Koperasi Karyawan Redrying Bojonegoro}

Koperasi Karyawan Redrying Bojonegoro (KAREB) memiliki visi dan misi yang dijadikan dasar dalam penetapan sasaran - sasaran strategik koperasi, sebagai berikut:

Visi, Mewujudkan Usaha Koperasi di bidang jasa dan perdagangan yang terpercaya dan terbaik di tingkat nasional maupun internasional

Misi

a. Meningkatkan kesejahteraan anggota dan karyawaan.

b. Memberikan pelayanan terbaik kepada seluruh pelanggan/mitra kerja.

c. Terus membangun dan mengembangkan semua unit usaha dengan sistem manajemen efektif dan efesien

Berdasarkan pengamatan terhadap koperasi dan wawancara kepada pengurus koperasi KAREB menghasilkan rumusan sasaran stategik koperasi sebagai berikut:

Perspektif Financial

Dalam perspektif ini dapat dilihat keberhasialan keuangan untuk menentukan tingkat kesehatan keuangan suatu organisasi. Koperasi KAREB menetapkan sasaran startegis, yaitu meningkatkan Pendapatan dan Profit / Sisa Hasil Usaha (SHU) Pendapatan dianggap sebagai penunjang pertumbuhan profit koperasi, meningkatan penggunaan asset dan Investasi, mendongkrak pendapatan. 
Perspektif Costumers

Perspektif ini difungsikan untuk mengidentifikasi segmen pasar dimana koperasi dapat terus sustain. Sasaran strategik yang dicapai Koperasi KAREB pada prspektif ini adalah, meningkatkan kepuasan pelanggan, meningkatkan kepercayaan pelanggan.

Perpektif Internal Business Process

Perspektif ini menggambarkan strategi - strategi organisasi mengarah pada proses bisnis internal koperasi yang terkait dengan penciptaan nilai produk dan layanan secara efektif dan efesien sehingga koperasi dapat berkembang pesat. Sasaran strategik yang dicapai Koperasi adalah, Meningkatkan Kualitas Produk Meningkatkan Kecepatan dan Mutu Pelayanan, Memanfaatkan Aset Secara Optimal

Perspektif Learning and Growth

Perspektif ini mengarah pada kemampuan koperasi untuk menyiapkan infrasturktur untuk ketiga perspektif lainya serta menciptakan sumber daya yang unggul dan kompeten. Sasaran strategik yang dicapai adalah, Mengembangankan Kompetensi Karyawaan, Meningkatkan Kepuasan Karyawaan.

\section{Rancangan Matriks Balanced Scorecard Koperasi}

Balanced Scorecard memiliki dua macam indikator kinerja, yaitu: lag indicator (ukuran hasil) atau disebut keberhasilan pencapaian sasaran strategik dan lead indicator (ukuran pemicu) atau pemicu untuk mencapai hasil yang dinginkan. Rancangan matriks Balanced Scorecard Koperasi dapat dilihat pada tabel berikut:

Tabel 2

Matriks Balanced Scorecard Koperasi Karyawan Redrying Bojonegoro

\begin{tabular}{|c|c|c|c|}
\hline \multirow[b]{2}{*}{ Sasaran Strategik } & \multicolumn{2}{|c|}{ Ukuran } & \multirow[b]{2}{*}{ Inisiatif Strategi } \\
\hline & $\begin{array}{l}\text { Lag Indicatros } \\
\text { (Ukuran Hasil) }\end{array}$ & $\begin{array}{l}\text { Lead Indicators } \\
\text { (Ukuran Pemicu) }\end{array}$ & \\
\hline $\begin{array}{l}\quad \text { Perspektif } \\
\text { Keuangan } \\
\\
\text { 1.Peningkatan } \\
\text { Pendapatan dan } \\
\text { Profitabilitas }\end{array}$ & $\begin{array}{l}\text { 1.Peningkatan } \\
\text { Pendapatan } \\
\text { 2. Pertumbuhan } \\
\text { Keuntungan / SHU }\end{array}$ & $\begin{array}{l}\text { 1. Persentase } \\
\text { Peningkatan } \\
\text { Pendapatan } \\
\text { 2. Persentase } \\
\text { Peningkatan Profit } \\
\text { Margin /SHU }\end{array}$ & $\begin{array}{l}\text { 1..Melakukan efeisensi } \\
\text { biaya produksi } \\
\text { 2.Meningkatkan hasil } \\
\text { produksi }\end{array}$ \\
\hline $\begin{array}{l}\text { 2.Peningkatan } \\
\text { Pengguanaan } \\
\text { Asset dan } \\
\text { Investasi }\end{array}$ & $\begin{array}{l}\text { 1.Tingkat } \\
\text { Pemanfaatan } \\
\text { Utilitas dari } \\
\text { Investasi } \\
\text { 2.Tingkat } \\
\text { Pemnfaatan Asset }\end{array}$ & 1.Peningkatan ROA & $\begin{array}{l}\text { 1.Memberikan kemudahan } \\
\text { investasi } \\
\text { 2.Pemanfaatan aset secara } \\
\text { optimal }\end{array}$ \\
\hline 3.Efisiensi biaya & 1.Penurunan biaya & $\begin{array}{l}\text { 1.Persentase } \\
\text { Peningkatan } \\
\text { Penghematan Biaya }\end{array}$ & $\begin{array}{l}\text { 1.Melakukan modifikasi } \\
\text { pada generator } \\
\text { 2. Peningkatan skill }\end{array}$ \\
\hline
\end{tabular}




\begin{tabular}{|c|c|c|c|}
\hline & & & $\begin{array}{l}\text { karyawan } \\
\text { Melalui pelatihan } \\
\text { sehingga menguragi } \\
\text { human error } \\
\text { 3.Menekan biaya rutin } \\
\text { perusahaan ( listrik, } \\
\text { telpon, perawatan } \\
\text { infrasruktur). }\end{array}$ \\
\hline $\begin{array}{l}\text { Perspektif } \\
\text { Pelanggan } \\
\text { 1.Peningkatan } \\
\text { kepuasan } \\
\text { pelanggan }\end{array}$ & $\begin{array}{l}\text { 1.Peningkatan } \\
\text { Costumer } \\
\text { Satisfaction }\end{array}$ & $\begin{array}{l}\text { 1.Peningkatan Hasil } \\
\text { Survey Kepauasan } \\
\text { Pelanggan }\end{array}$ & $\begin{array}{l}\text { 1.Selalu menjaga kualitas } \\
\text { produk/jasa } \\
\text { 2.Memberikan pelayanan } \\
\text { terbaik }\end{array}$ \\
\hline $\begin{array}{l}\text { 2.Peningkatan } \\
\text { Kepercayaan } \\
\text { Pelanggan }\end{array}$ & $\begin{array}{l}\text { 1.Costumer } \\
\text { Retention and } \\
\text { Acquisition }\end{array}$ & $\begin{array}{l}\text { 1.Pertambahan Jumlah } \\
\text { Pelanggan Baru } \\
\text { 2.Peningkatan Total } \\
\text { Jumlah Pelanggan }\end{array}$ & $\begin{array}{l}\text { 1.Menetapkan harga jual } \\
\text { yang bersaing } \\
\text { 2.Langsung terjun petani } \\
\text { atau pengusaha tembakau }\end{array}$ \\
\hline $\begin{array}{l}\text { Perspektif } \\
\text { Internal Bisnis } \\
\quad \text { Proses } \\
\end{array}$ & $\begin{array}{l}\text { 1.Menurunya } \\
\text { produk cacat }\end{array}$ & $\begin{array}{l}\text { 1. Penurunan Jumlah } \\
\text { produk yang } \\
\text { dikembalikan dan } \\
\text { produksi ulang }\end{array}$ & $\begin{array}{l}\text { 1. Meningkatkan kualitas } \\
\text { karyawan untuk mencegah } \\
\text { human error } \\
\text { 2.Selalu melakukan } \\
\text { perawatan dan perbaikan } \\
\text { aset }\end{array}$ \\
\hline $\begin{array}{l}\text { 2.Meningkatkan } \\
\text { kecepatan dan } \\
\text { mutu pelayanan }\end{array}$ & $\begin{array}{l}\text { 1. Response time } \\
\text { yang Baik }\end{array}$ & $\begin{array}{l}\text { 1.Peningkatan Rata- } \\
\text { Rata waktu } \\
\text { Peneyelesaian } \\
\text { Komplain }\end{array}$ & $\begin{array}{l}\text { 1. Meningkatkan kualitas } \\
\text { karyawan melalui } \\
\text { pelatihan } \\
\text { 2.Koordinasi antar } \\
\text { karyawan dalam } \\
\text { penyeselaian masalah } \\
\text { 3.Mengawasi dan } \\
\text { memotivasi karyawaan } \\
\text { lebih giat. }\end{array}$ \\
\hline $\begin{array}{l}\text { 3.Memaksimalkan } \\
\text { aset secara } \\
\text { optimal }\end{array}$ & $\begin{array}{l}\text { 1.Peningkatan } \\
\text { Aktivitas yang } \\
\text { memberi nilai } \\
\text { tambah }\end{array}$ & $\begin{array}{l}\text { 1.Peningkatan Capacity } \\
\text { utilitation rate }\end{array}$ & $\begin{array}{l}\text { 1. Memperluas pangsa } \\
\text { pasar } \\
\text { 2.Melakukan perawatan } \\
\text { berkala }\end{array}$ \\
\hline
\end{tabular}




\begin{tabular}{|c|c|c|c|}
\hline $\begin{array}{l}\text { Perspektif } \\
\text { Pembelajaran } \\
\text { dan } \\
\text { Pertumbuhan } \\
\text { 1.Meningkatkan } \\
\text { Produktivitas } \\
\text { karyawan }\end{array}$ & $\begin{array}{l}\text { 1.Produktivitas } \\
\text { Karyawaan Rata - } \\
\text { rata } \\
\text { 2.Peningkatan } \\
\text { Kemampuan } \\
\text { Karyawaan }\end{array}$ & $\begin{array}{l}\text { 1.Peningkatan } \\
\text { Persentase } \\
\text { Produktivitas } \\
\text { Karyawaan } \\
\text { 2.Peningkatan } \\
\text { Persentase Karyawaan } \\
\text { Terlatih }\end{array}$ & $\begin{array}{l}\text { 1.Meningkatkan intensitas } \\
\text { kepelatihan karyawan } \\
\text { sesuai kebutuhan }\end{array}$ \\
\hline $\begin{array}{l}\text { 2.Peningkatan } \\
\text { kepuasan } \\
\text { karyawan }\end{array}$ & $\begin{array}{l}\text { 1.Tingkat } \\
\text { Kepuasan } \\
\text { Karyawaan }\end{array}$ & $\begin{array}{l}\text { 1.Peningkatan Hasil } \\
\text { Survey Kepuasan } \\
\text { Karyawannya } \\
\text { 2.Persentase Turnover } \\
\text { Karyawaan }\end{array}$ & $\begin{array}{l}\text { 1. Pemberian gaji dan } \\
\text { insentif sesuai job } \\
\text { description masing- } \\
\text { masing } \\
\text { 2.Memberikan job } \\
\text { description sesuai dengan } \\
\text { kemampuan tiap-tiap } \\
\text { karyawannya } \\
\text { 3.Menjaga kultur kerja } \\
\text { yang kondusif }\end{array}$ \\
\hline
\end{tabular}

\section{Strategy Map Koperasi Karyawan Redrying Bojonegoro}

Tahapan ini menggambarkan peta hubungan sebab akibat yang ada dalam rumusan sasaran strategik antar masing - masing perspektif Balanced Scorecard Koperasi, seperti yang terlihat pada gambar berikut: 


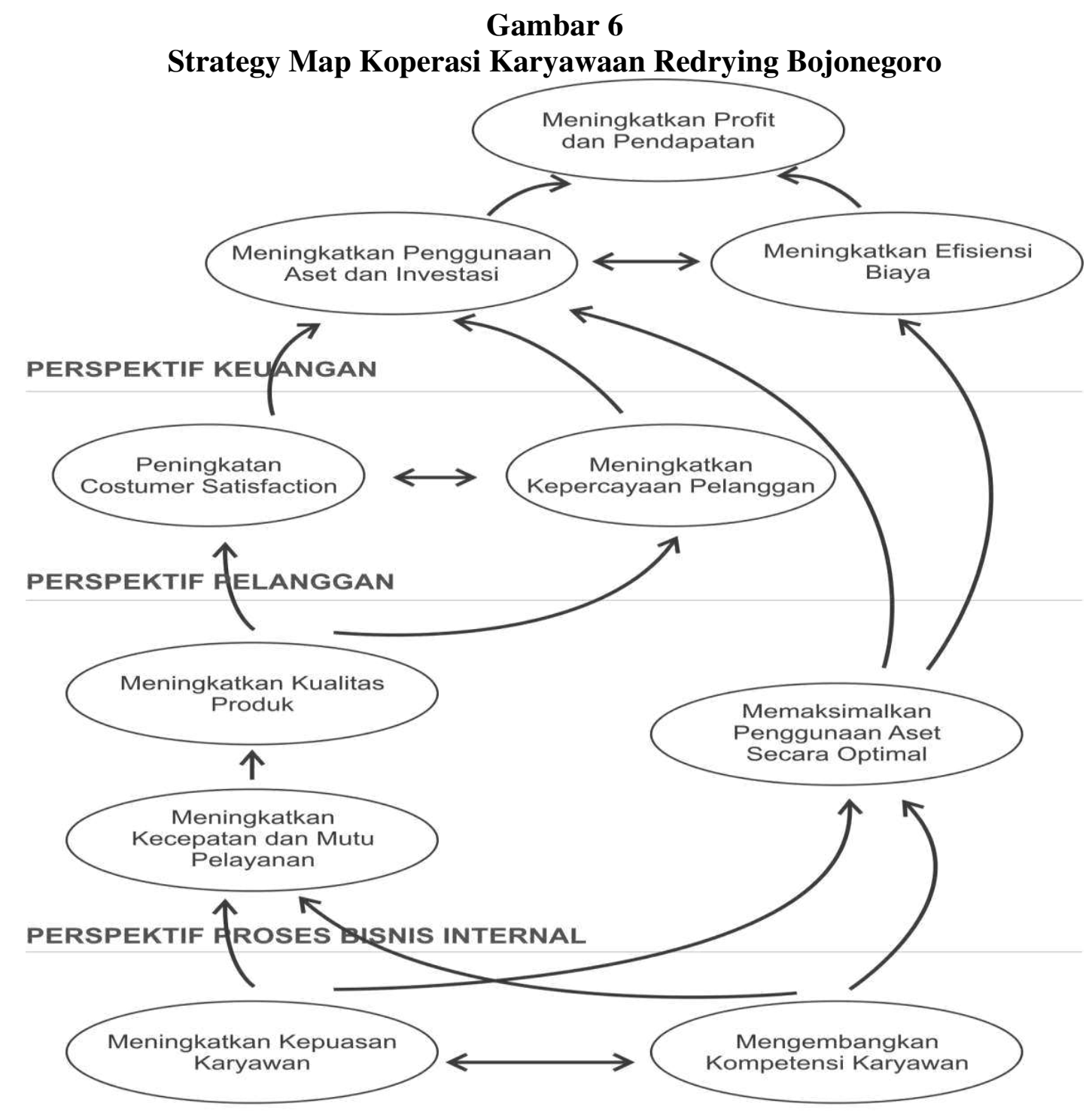

PERSPEKTIF PEMBELAJARAN DAN PERTUMBUHAN

Hubungan tersebut dimulai dengan meningkatkan kompetensi karyawan dan peningkatan kepuasan karyawaan sehingga dari kedua sasaran strategis perspektif learning and growth akan dampak pada kualitas produk, kecapatan dan mutu pelayanan serta pemanfaatan aset secara optimal. Terciptanya produk dan pelayanan yang berkualitas diharapkan mampu meningkatkan konsumen sehingga dapat pula menarik konsumen baru untuk berinvestasi.. Jika pelanggan telah mendapatkan kepuasan dan pertumbuhan konsumen terpenuhi maka akan meningkatkan pendapatan serta profit /SHU Koperasi, sehingga koperasi dapat mengembangkan usahanya.

\section{Penentuan Key Performance Indicator (KPI)}

Tahapan ini merupakan tahap dimana KPI dari rancangan awal Balanced Scorecard bisa digunakan sebagai indikator kinerja untuk pengukuran kinerja selanjutnya. Sehingga hasil dari pengukuran kinerja menjadi valid dan dapat dijadikan masukan untuk sistem pengukuran kinerja Koperasi 
Validasi KPI dilakukan oleh pengurus Koperasi. Pengurus Koperasi dianggap paling mengetahui secara global kegiatan koperasi bagi dari segi manajemen dan operasional. Dari Proses validasi dilakukan dengan Focus Group Discusion sehingga terbentuk satu kesepakatan bersama maka diperoleh KPI Koperasi pada tabel berikut:

Tabel 3

KPI (Key Performance Indicators)

\begin{tabular}{|c|c|c|}
\hline Perspektif & $\begin{array}{c}\text { Lag Indicators } \\
\text { Hasil) }\end{array}$ & $\begin{array}{c}\text { Lead Indicators } \\
\text { Pemicu) }\end{array}$ \\
\hline \multirow[t]{5}{*}{ Finance } & \multirow{2}{*}{$\begin{array}{l}\text { - Meningkatkan Profit dan } \\
\text { Pendapatan }\end{array}$} & 1. Peningkatan Pertumbuhan Pendapatan \\
\hline & & 2. Peningkatan Laba /SHU \\
\hline & \multirow{2}{*}{$\begin{array}{l}\text { - Meningkatkan Penggunaan Asset } \\
\text { dan Investasi }\end{array}$} & 3. Peningkatan ROA \\
\hline & & 4. Peningkatan ROE \\
\hline & - Meningkatkan Efisiensi Biaya & $\begin{array}{l}\text { 5. Persentase Peningkatan Penghematan } \\
\text { Biaya }\end{array}$ \\
\hline \multirow[t]{3}{*}{ Costumers } & $\begin{array}{l}\text { - Meningkatkan Kepuasan } \\
\text { Pelanggan }\end{array}$ & $\begin{array}{l}\text { 6.Peningkatan Hasil Survey Kepuasan } \\
\text { Pelanggan }\end{array}$ \\
\hline & \multirow[t]{2}{*}{$\begin{array}{l}\text { - Meningkatkan Kepercayaan } \\
\text { Pelanggan }\end{array}$} & 7. Pertambahan Jumlah Pelanggan Baru \\
\hline & & 8. Peningkatan Total Pelanggan \\
\hline \multirow[t]{3}{*}{$\begin{array}{l}\text { Internal } \\
\text { Bussines } \\
\text { Process }\end{array}$} & - Meningkatkan Kualitas Produk & $\begin{array}{l}\text { 9. Penurunan jumlah produk yang } \\
\text { dikembalikan dan produksi ulang }\end{array}$ \\
\hline & $\begin{array}{l}\text { - Meningkatkan Kecepatan dan } \\
\text { Mutu Pelayanan }\end{array}$ & $\begin{array}{l}\text { 10. Peningkatan Rata - rata waktu } \\
\text { penyelesain komplain }\end{array}$ \\
\hline & $\begin{array}{l}\text { - Memaksimalkan Aset secara } \\
\text { Optimal }\end{array}$ & 11. Peningkatan Capacity Utilitation Rate \\
\hline \multirow[t]{3}{*}{$\begin{array}{l}\text { Learning } \\
\text { and } \\
\text { Growth }\end{array}$} & \multirow[t]{2}{*}{$\begin{array}{l}\text { - Meningkatkan Produktifitas } \\
\text { Karyawaan }\end{array}$} & $\begin{array}{l}\text { 12. Peningkatan Produktivitas } \\
\text { Karyawaan }\end{array}$ \\
\hline & & $\begin{array}{l}\text { 13. Peningkatan Persentase Karyawaan } \\
\text { Terlatih }\end{array}$ \\
\hline & $\begin{array}{l}\text { - Meningkatkan Kepuasan } \\
\text { Karyawaan }\end{array}$ & $\begin{array}{l}\text { 14. Peningkatan Hasil Survey Kepuasan } \\
\text { Karyawaan }\end{array}$ \\
\hline
\end{tabular}

Sumber: Pengolahan Data Primer

Berdasarkan KPI yang telah divalidasi diatas maka dilakukan identifikasi ukuran kinerja koperasi telah disesuaikan dengan karakteristik Koperasi kemudian terbentuklah spesifikasi pengukuran kinerja Koperasi dengan ukuran yang spesifik, dapat diukur, dapat dicapai, dan 
berdasarkan rentan waktu menurut masing - masing perspektif Balanced Scorecard yang disajikan dalam tabel berikut ini:

\section{Pembobotan Prioritas Kinerja dengan Analytical Hierarcy Process}

Pada tahap ini dilakukan proses pembobotan pada setiap indikator kinerja (KPI) yang telah divalidasi oleh dewan pengurus dan pengelola Koperasi Karyawaan Redrying Bojonegoro dengan metode Analytical Hierarchy Process (AHP), yaitu dengan kuisioner perbandingan berpasangan.

Proses pembobotan KPI dilakukan dengan data yang diperoleh dari Focus Group Discusion (FGD), selanjutnya dibobotkan. Pembobotan tersebut diolah dengan menggunakan software Expert Choice 2000. Berdasarkan hasil pengolahan kuisioner perbandingan berpasangan didapat hirarki penentuan pembobotan Perspektif Balanced Scorecard. Menunjukan prioritas antar perspektif Balanced Scorecard, yaitu financial, costumers, internal process bussines, dan learning and growth, manakah diantara perspektif tersebut yang lebih menjadi prioritas dalam pencapaian strategi perusahaan.

1. Pembobotan Lokal Lag Indicators (Ukuran Hasil)

Menunjukan prioritas lag indicators dengan lag indicators lainya dalam satu perspektif. Pada tingkatan ini beberapa lag indicators dalam satu perspektif akan diukur bobotnya sehingga akan diketahui lag indicator mana yang menjadi prioritas.

2. Pembobotan Global KPI

Keseluruhan KPI dalam Balanced Scorecard Koperasi yang menjadi ukuran pemicu akan diukur bobot masing - masing, sehingga dapat diketahui KPI mana yang menjadi prioritas dalam pencapaian strategi perusahaan.

Berdasarkan hasil pengolahan data kuisioner perbandingan berpasangan diperoleh bobot prioritas perspektif Balanced Scorecard, bobot lokal lag indicators, dan bobot global KPI Koperasi yang tersajikan dalam tabel berikut:

Tabel 4

Hasil Pembobotan Proiritas Kinerja dengan AHP

\begin{tabular}{|c|c|l|c|l|c|}
\hline Perspektif & Bobot & $\begin{array}{l}\text { Lag Indicators } \\
\text { (Ukuran Hasil) }\end{array}$ & $\begin{array}{c}\text { Bobot } \\
\text { Lokal }\end{array}$ & KPI & $\begin{array}{c}\text { Bobot } \\
\text { Global }\end{array}$ \\
\hline Finance & $\mathbf{0 . 4 1 8}$ & $\begin{array}{l}\text { • Meningkatkan } \\
\text { Profit dan } \\
\text { Pendapatan }\end{array}$ & 0.54 & $\begin{array}{l}\text { 1.Peningkatan Laba } \\
\text { /SHU }\end{array}$ & 0.071 \\
\cline { 3 - 5 } & & $\begin{array}{l}\text { 2.Peningkatan } \\
\text { Pertumbuhan } \\
\text { Pendapatan }\end{array}$ & 0.213 \\
\cline { 3 - 5 } & $\begin{array}{l}\text { - Meningkatkan } \\
\text { Penggunaan Asset } \\
\text { dan Investasi }\end{array}$ & 0.297 & 3.ROA & 0.039 \\
\cline { 3 - 5 } & $\begin{array}{l}\text { - Meningkatkan } \\
\text { Efisiensi Biaya }\end{array}$ & 0.163 & $\begin{array}{l}\text { 4.Peningkatan } \\
\text { Efisiensi Biaya }\end{array}$ & 0.064 \\
\hline
\end{tabular}




\begin{tabular}{|c|c|c|c|c|c|}
\hline \multirow[t]{3}{*}{ Costumers } & \multirow[t]{3}{*}{0.271} & $\begin{array}{l}\text { - Meningkatkan } \\
\text { Kepuasan Pelanggan }\end{array}$ & 0.333 & $\begin{array}{l}\text { 6.Peningkatan Hasil } \\
\text { Survey Kepuasan } \\
\text { Pelanggan }\end{array}$ & 0.069 \\
\hline & & \multirow[t]{2}{*}{$\begin{array}{l}\text { - Meningkatkan } \\
\text { Kepercayaan } \\
\text { Pelanggan }\end{array}$} & \multirow[t]{2}{*}{0.667} & $\begin{array}{l}\text { 7.Pertambahan } \\
\text { Jumlah Pelanggan } \\
\text { Baru }\end{array}$ & 0.046 \\
\hline & & & & $\begin{array}{l}\text { 8.Peningkatan Total } \\
\text { Pelanggann }\end{array}$ & 0.138 \\
\hline \multirow[t]{3}{*}{$\begin{array}{l}\text { Internal } \\
\text { Bussines } \\
\text { Process }\end{array}$} & \multirow[t]{3}{*}{0.12} & $\begin{array}{l}\text { - Meningkatkan } \\
\text { Kualitas Produk }\end{array}$ & 0.594 & $\begin{array}{l}\text { 9.Penurunan jumlah } \\
\text { produk yang } \\
\text { dikembalikan dan } \\
\text { produksi ulang }\end{array}$ & 0.061 \\
\hline & & $\begin{array}{l}\text { - Meningkatkan } \\
\text { Kecepatan dan Mutu } \\
\text { Pelayanan }\end{array}$ & 0.249 & $\begin{array}{l}\text { 10.Peningkatan } \\
\text { Rata - rata waktu } \\
\text { penyelesain } \\
\text { komplain }\end{array}$ & 0.026 \\
\hline & & $\begin{array}{l}\text {-Memaksimalkan } \\
\text { Aset secara Optimal }\end{array}$ & 0.157 & $\begin{array}{l}\text { 11.Peningkatan } \\
\text { Capacity Utilitation } \\
\text { Rate }\end{array}$ & 0.016 \\
\hline \multirow[t]{3}{*}{$\begin{array}{l}\text { Learning } \\
\text { and } \\
\text { Growth }\end{array}$} & \multirow[t]{3}{*}{0.191} & \multirow[t]{2}{*}{$\begin{array}{l}\text { - Meningkatkan } \\
\text { Produktifitas } \\
\text { Karyawaan }\end{array}$} & \multirow[t]{2}{*}{0.25} & $\begin{array}{l}\text { 12. Peningkatan } \\
\text { Produktivitas } \\
\text { Karyawaan }\end{array}$ & 0.011 \\
\hline & & & & $\begin{array}{l}\text { 14. Peningkatan } \\
\text { Persentase } \\
\text { Karyawaan Terlatih }\end{array}$ & 0.032 \\
\hline & & $\begin{array}{l}\text { - Meningkatkan } \\
\text { Kepuasan } \\
\text { Karyawaan }\end{array}$ & 0.75 & $\begin{array}{l}\text { 15. Peningkatan } \\
\text { Hasil Survey } \\
\text { Kepuasan } \\
\text { Karyawaan }\end{array}$ & 0.097 \\
\hline
\end{tabular}

Sumber: Pengolahan Data AHP

Dari hasil pengolahan diatas maka dapat diketahui perspektif keuangan mendapatkan prioritas utama dengan bobot $41,8 \%$. Hal ini menunjukan bahwa keuanga tetap menjadi tujuan utama Koperasi . Kemudian perspektif pelanggan dengan bobot 27,1\%, kemudian perspektif pembelajaran dan pertumbuhan dengan bobot $19,1 \%$ dan terakhir perspektif proses bisnis internal yaitu dengan bobot sebesar $12 \%$.

1. Analisis Bobot Lokal Lag Indicators

Pada perspektif keuangan indikator pengkatan profit dan pendapatan menjadi prioritas utama dengan bobot $54 \%$. Prioritas selanjutnya adalah peningkatan penggunaan aset dan invesatsi dengan bobot $29,7 \%$ kemudian peningkatan efisensi biaya dengan bobot $16,3 \%$..Pada perspektif pelanggan, peningkatan kepercayaan pelanggan menjadi prioritas utama dengan bobot $66,7 \%$ sedangkan peningkatan kepuasan pelanggan 
mendapat bobot 33,3\%. Hal ini menunjukan pelanggan mendapatkan perhatian dengan baik.Pada perspektif proses bisnis internal, peningkatan kualitas produk mendapat prioritas utama dengan bobot 59,4\%, kemudian peningkatan kecepatan dan mutu pelayanan dengan bobot $24,9 \%$, serta terakhir memaksimalkan aser secara optimal mendapat bobot $15,7 \%$. Pada persepektif pembelajaran dan pertumbuhan, peningkatan kepuasaan karyawaan menjadi prioritas utama dengan bobot $75 \%$ dan peningkatan produktifitas karyawaan memperoleh bobot $25 \%$. Hal ini menunjukan bahwa kepuasan karyawaan menjadi prioritas utama dikarenakan seluruh karyawaan adalah pemegang kepemilikan koperasi

\section{Analisis Bobot Global KPI}

Berdasarkan hasil pembobotan kuisioner perbandingan dan pengolahan software expert choice 2000 maka diperoleh prioritas sebagai berikut:

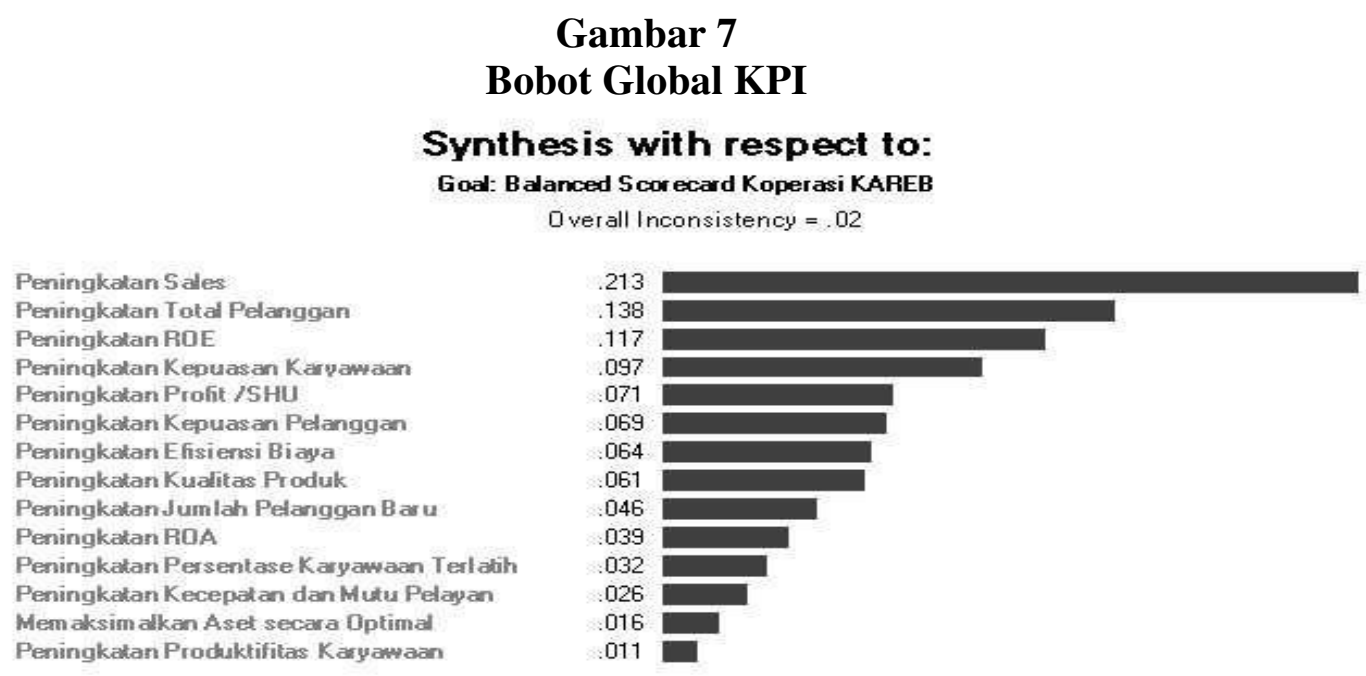

\section{Sumber: Data Pengolahan AHP}

Berdasarkan grafik diatas dapat diketahui nilai inkonsistensi kurang dari 0,1 yakni sebesar 0,02 . Hal ini dapat dikatakan pembobotan global diatas valid dan konsisten.

Dari hasil pembobotan global KPI yang menjadi prioritas utama adalah peningkatan pendapatan yaitu dengan bobot $21,3 \%$, kemudian peningkatan total pelanggan dengan bobot $13,8 \%$, peningkatan ROE dengan bobot $11,7 \%$, peningkatan kepuasan karyawaan dengan bobot $9,7 \%$ serta peningkatan profit/ SHU dengan bobot 7,1\%. Berikut adalah 5 (lima) prioritas utama KPI yang menjadi sasaran utama dalam meningkatkan nilai koperasi agar tetap sustain berkembang.

Model Balanced Scorecard Koperasi Karyawaan Redrying Bojonegoro

Tabel 5

Model Balanced Scorecard Koperasi Karyawaan Bojonegoro

\begin{tabular}{|c|c|c|c|c|c|c|}
\hline Perspektif & $\begin{array}{c}\text { Sasaran } \\
\text { Strategis }\end{array}$ & Indikator & $\begin{array}{c}\text { Realis } \\
\text { asi }\end{array}$ & $\begin{array}{c}\text { Target } \\
(\mathbf{b})\end{array}$ & $\begin{array}{c}\text { Bobot } \\
(\mathbf{c})\end{array}$ & $\begin{array}{c}\text { Skor } \\
((\mathbf{a}) \mathbf{b}) \mathbf{x c})\end{array}$ \\
\hline
\end{tabular}




\begin{tabular}{|c|c|c|c|c|c|}
\hline & & & (a) & & \\
\hline \multirow[t]{5}{*}{ Finance } & \multirow[t]{2}{*}{$\begin{array}{l}\text { - Meningkatkan } \\
\text { Profit dan } \\
\text { Pendapatan }\end{array}$} & $\begin{array}{l}\text { 1.Peningkatan } \\
\text { Laba /SHU }\end{array}$ & & $5 \%$ & $7,1 \%$ \\
\hline & & $\begin{array}{l}\text { 2.Peningkatan } \\
\text { Pertumbuhan } \\
\text { Pendapatan }\end{array}$ & & $15 \%$ & $21,3 \%$ \\
\hline & \multirow[t]{2}{*}{$\begin{array}{l}\text { - Meningkatkan } \\
\text { Penggunaan } \\
\text { Asset dan } \\
\text { Investasi }\end{array}$} & 3.ROA & & 9,00 & $3,9 \%$ \\
\hline & & 4.ROE & & 10,00 & $11,7 \%$ \\
\hline & $\begin{array}{l}\text { - Meningkatkan } \\
\text { Efisiensi Biaya }\end{array}$ & $\begin{array}{l}\text { 5.Peningkatan } \\
\text { Efisiensi Biaya }\end{array}$ & & $15 \%$ & $6,4 \%$ \\
\hline \multirow[t]{3}{*}{ Costumers } & $\begin{array}{l}\text { - Meningkatkan } \\
\text { Kepuasan } \\
\text { Pelanggan }\end{array}$ & $\begin{array}{l}\text { 6.Peningkatan } \\
\text { Hasil Survey } \\
\text { Kepuasan } \\
\text { Pelanggan }\end{array}$ & & nilai 5 & $6,9 \%$ \\
\hline & \multirow[t]{2}{*}{$\begin{array}{l}\text { - Meningkatkan } \\
\text { Kepercayaan } \\
\text { Pelanggan }\end{array}$} & $\begin{array}{l}\text { 7.Pertambahan } \\
\text { Jumlah Pelanggan } \\
\text { Baru }\end{array}$ & & $7 \%$ & $4,6 \%$ \\
\hline & & $\begin{array}{l}\text { 8.Peningkatan } \\
\text { Total Pelanggann }\end{array}$ & & $7 \%$ & $13,8 \%$ \\
\hline
\end{tabular}

\begin{tabular}{|c|c|c|c|c|}
\hline \multirow[t]{3}{*}{$\begin{array}{l}\text { Internal } \\
\text { Bussines } \\
\text { Process }\end{array}$} & $\begin{array}{l}\text { - Meningkatkan } \\
\text { Kualitas Produk }\end{array}$ & $\begin{array}{l}\text { 9.Penurunan } \\
\text { jumlah produk } \\
\text { yang } \\
\text { dikembalikan dan } \\
\text { produksi ulang }\end{array}$ & $1 \%$ & $6,1 \%$ \\
\hline & $\begin{array}{l}\text { - Meningkatkan } \\
\text { Kecepatan dan } \\
\text { Mutu Pelayanan }\end{array}$ & $\begin{array}{l}\text { 10.Peningkatan } \\
\text { Rata - rata waktu } \\
\text { penyelesain } \\
\text { komplain }\end{array}$ & 1 hari & $2,6 \%$ \\
\hline & $\begin{array}{l}\text { Memaksimalka } \\
\text { n Aset secara } \\
\text { Optimal }\end{array}$ & $\begin{array}{l}\text { 11.Peningkatan } \\
\text { Capacity } \\
\text { Utilitation Rate }\end{array}$ & $90 \%$ & $1,6 \%$ \\
\hline $\begin{array}{l}\text { Learning } \\
\text { and }\end{array}$ & $\begin{array}{l}\text { - Meningkatkan } \\
\text { Produktifitas }\end{array}$ & $\begin{array}{l}\text { 12. Peningkatan } \\
\text { Produktivitas }\end{array}$ & $\begin{array}{c}\mathrm{Rp} \\
30.000 .0\end{array}$ & $1,1 \%$ \\
\hline
\end{tabular}




\begin{tabular}{|c|c|c|c|c|}
\hline \multirow[t]{3}{*}{ Growth } & \multirow[t]{2}{*}{ Karyawaan } & Karyawaan & $\begin{array}{c}00 \\
\text { /karyaw } \\
\text { aan }\end{array}$ & \\
\hline & & $\begin{array}{l}\text { 14. Peningkatan } \\
\text { Persentase } \\
\text { Karyawaan } \\
\text { Terlatih }\end{array}$ & $35 \%$ & $3,2 \%$ \\
\hline & $\begin{array}{l}\text { - Meningkatkan } \\
\text { Kepuasan } \\
\text { Karyawaan }\end{array}$ & $\begin{array}{l}\text { 15. Peningkatan } \\
\text { Hasil Survey } \\
\text { Kepuasan } \\
\text { Karyawaan }\end{array}$ & nilai 5 & $9,7 \%$ \\
\hline Score Card & \multicolumn{3}{|c|}{ Score $=\frac{\text { Realisasi }}{\text { Target }} x$ Bobot } & $100 \%$ \\
\hline
\end{tabular}

\section{Simpulan}

Pengukuran kinerja yang dilakukan Koperasi saat ini hanya berorinetasi pada aspek keuangan saja sehingga tidak dapat memberikan ukuran tentang pemicu penyebab naik turunya kinerja keuangan itu sendiri. Meskipun kinerja keuangan meningkat tetapi secara keseluruhan kinerja yang dilakukan belum mencapai target yang ditetapkan koperasi. Sasaran strategik pada tiap - tiap perspektif balanced scorecard mennghasilkan simpulan bahwa, pada perspektif keuangan menetapkan untuk meningkatkan profit dan pendapatan, meningkatkan penggunaan aset dan investasi, serta meningkatkan efisiensi biaya. Pada perspektif pelanggan menetapkan sasaran strategik yaitu: meningkatkan kepercayaan pelanggan dan meningkatkan kepuasan pelanggan. Pada perspektif proses bisnis internal menetapkan sasaran strategis berupa meningkatkan kualitas produk, meningkatkan kecepatan dan mutu pelayanan, serta memaksimalkan aset secara optimal. Pada perspektif pembelajaran dan pertumbuhan menetapkan sasaran strategis meningkatkan produktifitas karyawaan dan meningkatkan kepuasan karyawaan. 


\section{Daftar referensi}

Bititci U S, Carrie A S, McDevitt L G, "Integrated Performance Measurement Systems: A Development Guide", International Journal of Operations and Production Management, vol 17 no 6, May/June 1997, MCB University Press, ISSN 0144-3577, pp. 522-535.

Brandon Charles H. Dratina Ralph E., 1997. Management - Strategy and Control. McGraw-Hill Inc. Canada

Carrie A S and Macintosh, 1992, UK Research in Manufacturing Systems Integration, Integration in Production Management Systems, Pels and Worthman, Elsevier, pp 323-336.

Ferreira, Reginaldo Barreiros and Max, Roberto Protil. 2010. Proposal of A Strategic Management Simulation Model For Agro-Industrial Cooperatives. Campo Grande. Sociedade Brasileira de Economia, Administração e Sociologia Rural

Kaplan, Robert. S \& David P. Norton. 1996.The Balanced Scorecard: Translating Strategy into Action. United States of America : The President and Fellows of Harvard College

Kaplan, Robert and David P. Norton. 2006. Using The Balanced Scorecard to Create Corporate Synergies. Harvard Bussiness School Press

Kaplan, Robert and David P. Norton. 2007. Using The Balanced Scorecard as a Strategic Management System. Harvard Bussiness School Press.

Najmi, Manoochehr, et all. 2005. A Framework to Review Performance Measurement System. Bussines Process Management Journal Vol.11 No.2 pp. 109-122.

Niven. PR. 2003. Balanced Scorecard Step by Step for Government and Nonprofit Agencies. John Wiley and Sons. New Jersey 